\title{
Penurunan Kadar Torium dan Radioaktivitas dalam Limbah Cair Proses Pengolahan Monasit PLUTHO Menggunakan Koagulan $\mathrm{FeSO}_{4}$
}

\section{Reduction of Thorium and Radioactivity Contents in Liquid Waste of PLUTHO Monazite Treatment Process using $\mathrm{FeSO}_{4}$ Coagulant}

\author{
Dany Poltak Marisi ${ }^{1,3^{*}}$, Suprihatin ${ }^{2}$, Andes Ismayana ${ }^{2}$ \\ ${ }^{1}$ Program Pascasarjana Pengelolaan Sumber Daya Alam dan Lingkungan - IPB \\ Jl. Raya Pajajaran, Kampus IPB Baranangsiang, Bogor, Indonesia, 16144 \\ ${ }^{2}$ Departemen Teknologi Industri Pertanian, Fakultas Teknologi Pertanian - IPB \\ Jl. Lingkar Akademik, Kampus IPB Dramaga, Bogor, Indonesia, 16680 \\ ${ }^{3}$ Pusat Teknologi Bahan Galian Nuklir - BATAN \\ Jl. Lebak Bulus Raya No.09, Pasar Jumat, Jakarta, Indonesia, 12440 \\ *E-mail: dany.poltak.m@batan.go.id
}

Naskah diterima: 26 April 2018, direvisi: 25 Mei 2018, disetujui: 31 Mei 2018

DOI: $10.17146 /$ eksplorium.2018.39.1.4276

\begin{abstract}
ABSTRAK
Pemisahan unsur radioaktif dan logam tanah jarang yang dilakukan di PLUTHO menghasilkan limbah yang masih mengandung torium dan uranium. Limbah yang dihasilkan memerlukan pengolahan lanjutan agar ramah lingkungan. Tujuan penelitian adalah menurunkan kadar torium dan radioaktivitas dalam limbah cair proses pengolahan monasit pilot plant PLUTHO menggunakan koagulan fero sulfat. Pilot Plant PLUTHO merupakan suatu fasilitas yang didirikan untuk untuk memisahkan uranium, torium, dan logam tanah jarang (LTJ) dari mineral monasit dan mineral lainnya dalam skala pilot. Perlakuan variasi yang dilakukan pada penelitian adalah dosis koagulan dan $\mathrm{pH}$. Pengukuran kadar torium dilakukan dengan metode Spektrofotometer UV-Vis, sedangkan pengukuran radioaktivitas dilakukan dengan alat ukur radiasi Ludlum Model 1000 Scaler. Hasil penelitian menunjukkan kondisi optimum koagulasi pada $\mathrm{pH} 8,0$ dengan dosis koagulan $\mathrm{FeSO}_{4} 225 \mathrm{mg} / \mathrm{L}$ yang dapat menurunkan kadar torium sebesar 45,20\% dan menurunkan radioaktivitas sebesar $100 \%$ dari kadar torium dan radioaktivitas awal yaitu $0,73 \mathrm{mg} / \mathrm{L}$ dan $1,35 \mathrm{~Bq} / \mathrm{g}$.
\end{abstract}

Kata kunci: limbah cair, monasit, $\mathrm{FeSO}_{4}$, torium, radioaktivitas

\begin{abstract}
The separation of radioactive and rare earth mineral carried out in PLUTHO produces waste that still contains thorium and uranium. The resulting waste requires further processing to be environmentally friendly. The purpose of study is to reduce thorium content and radioactivity in liquid waste of PLUTHO monazite treatment process using ferro sulphate coagulant. PLUTHO Pilot Plant is one of facility that built to dissociate uranium, thorium and light rare earth from mineral of monazite. Variations of treatments applied in the research are coagulant dosage and $\mathrm{pH}$. Thorium content is measured by Spectrophotometer UV-Vis method, whereas radioactivity is measured by radiation counting meter Ludlum Model 1000 Scaler. The result shows that the optimum condition of coagulation is in $\mathrm{pH} 8,0$ with concentration of ferro sulphate $225 \mathrm{mg} / \mathrm{L}$ which may reduce thorium content up to $45,20 \%$ and reduce radioactivity to $100 \%$ out of its initial thorium content and radioactivity as much as $0,73 \mathrm{mg} / \mathrm{L}$ and $1,35 \mathrm{~Bq} / \mathrm{g}$, respectively.
\end{abstract}

Keywords: liquid waste, monazite, $\mathrm{FeSO}_{4}$, thorium, radioactivity 


\section{PENDAHULUAN}

Monasit $\quad\left((\mathrm{Ce}, \mathrm{La}, \mathrm{Y}, \mathrm{Th}) \mathrm{PO}_{4}\right) \quad$ adalah senyawa fosfat logam tanah jarang yang mengandung 50-70\% oksida logam tanah jarang/Rare Earth [1] dan merupakan salah satu mineral ikutan pada proses penambangan timah. Monasit dari penambangan timah di Pulau Bangka mengandung unsur-unsur yang memiliki nilai ekonomis cukup tinggi, diantaranya oksida logam tanah jarang $\left(\mathrm{RE}_{2} \mathrm{O}_{3}\right)$ 58,97 \%, uranium (U) 0,298\%, torium (Th) 4,147\%, dan fosfat $\left(\mathrm{PO}_{4}\right) 23,712$ $\%$ [2]. Terdapatnya kadar torium yang cukup tinggi pada monasit membuat monasit bersifat radioaktif dan memancarkan radiasi.

Pada pengolahan monasit dilakukan proses pemisahan torium, uranium, dan logam tanah jarang (LTJ). Pemisahan unsurunsur tersebut dapat dipisahkan melalui pengolahan kimiawi seperti pengendapan, ekstraksi, penukar ion, dan adsorpsi [3]. Proses pemisahan yang banyak digunakan dan telah dikembangkan saat ini yaitu proses pengendapan. Pada proses pengendapan, terdiri dari dua metode yaitu metode asam dan metode basa. Metode basa merupakan metode yang digunakan dan dikembangkan dalam pengolahan monasit di pilot plant PLUTHO, Pusat Teknologi Bahan Galian Nuklir-BATAN. Pilot plant PLUTHO merupakan suatu fasilitas yang didirikan dalam skala pilot untuk memisahkan uranium, torium, dan logam tanah jarang dari mineral monasit yang merupakan produk samping dari penambangan timah. Selain itu, pilot plant juga dapat dimanfaatkan untuk pengolahan mineral atau bahan baku lainnya yang mengandung uranium, torium, dan LTJ seperti slag II peleburan timah [3]. Pada metode basa unsur pengotor berupa oksida logam seperti fosfat (P), kalsium (Ca), aluminium ( $\mathrm{Al})$, besi $(\mathrm{Fe})$, mangan $(\mathrm{Mn})$, timah (Sn), dan silikon (Si) dapat dihilangkan [4]. Proses pengolahan monasit dengan metode basa terdiri dari beberapa tahapan yaitu preparasi monasit, dekomposisi, pelarutan residu secara selektif atau parsial, pengendapan (U,Th)OH, dan pengendapan $\mathrm{RE}(\mathrm{OH})_{3}$ [2].

Kadar torium yang masih terdapat pada limbah cair pengolahan monasit mengakibatkan limbah cair tersebut menjadi bersifat radioaktif. Apabila limbah cair yang bersifat radioaktif masuk ke dalam saluran air ataupun lingkungan, maka akan menyebabkan efek radiasi kepada makhluk hidup yang terpapar atau masuk ke dalam tubuh makhluk hidup tersebut. Efek radiasi yang akan terjadi pada makhluk hidup dapat berupa efek deterministik dan efek stokastik. Efek deterministik akan muncul apabila ambang dosis terlampaui dan keparahan dari efek ini akan semakin meningkat seiring dengan meningkatnya dosis yang diterima seperti pengelupasan kulit (eritema), luka bakar, katarak, dan kemandulan pada seseorang. Pada efek stokastik jumlah dosis radiasi tidak mempengaruhi tingkat keparahan efek, tetapi hanya mempengaruhi kemungkinan timbul efek tersebut seperti kanker dan leukemia [5]. Oleh karena itu, limbah cair yang bersifat radioaktif tersebut perlu dilakukan pengolahan terlebih dahulu agar limbah cair tersebut aman bagi lingkungan. Tingkat radioaktivitas pada limbah radioaktif dikatakan aman bagi lingkungan apabila mencapai nilai di bawah atau sama dengan Tingkat Klierens yang mengacu pada Peraturan Kepala Badan Pengawas Tenaga Nuklir No. 16 tahun 2012 tentang Tingkat Klierens [6].

Pengolahan limbah cair terdiri dari pengolahan secara fisika, kimia, dan biologi [7]. Koagulasi merupakan salah satu proses 
pengolahan limbah cair secara kimia. Proses koagulasi biasanya dilakukan dengan membubuhkan koagulan untuk menghilangkan partikel-partikel yang tidak mudah mengendap, logam-logam berat, senyawa fosfor, dan zat organik beracun. Dasar prinsip koagulasi adalah peristiwa destabilisasi pada partikel-partikel koloid dimana gaya tolak-menolak (repulsi) di antara partikel-partikel tersebut dikurangi ataupun ditiadakan [8]. Bahan kimia yang dapat digunakan sebagai koagulan yaitu kapur, alum, dan polielektrolit (organik sintesis). Polielektrolit dapat berupa kation, anion, nonionik, dan Miccellaneous. Selain itu juga garam-garam besi seperti feri klorida dan fero sulfat dapat dipergunakan pula sebagai koagulan [9].

Penelitian mengenai pengolahan limbah cair yang bersifat radioaktif dengan proses kimia telah banyak dilakukan. Akan tetapi sifat radioaktif pada limbah cair tersebut sebagian besar bersumber dari unsur uranium maupun unsur lain yang bersifat radioaktif sama seperti torium. Salah satu penelitian pengolahan limbah cair yang bersifat radioaktif melalui proses koagulasi telah dilakukan [10]. Penelitian tersebut dilakukan terhadap limbah cair yang sifat radioaktifnya bersumber dari unsur fluor dan hasil yang diperoleh yaitu koagulan $\mathrm{CaCl}_{2}$ merupakan jenis koagulan yang optimal dalam penurunan unsur fluor dalam limbah cair. Selain itu $\mathrm{pH}$ dan dosis koagulan optimal pada penelitian tersebut yaitu $\mathrm{pH} 8$ dan $1,3 \mathrm{~mol} / \mathrm{L}$.

Di samping itu, penelitian lainnya juga telah dilakukan yaitu optimasi jumlah tawas dan kapur untuk koagulasi air keruh dengan penanda radioisotop Iodine-131 [11]. Berdasarkan hasil penelitian diperoleh jumlah dosis optimal tawas dan kapur masing-masing sebesar $41,817 \mathrm{mg} \mathrm{L}^{-1}$ dan $0,0213 \mathrm{~g}$ untuk mengendapkan $300 \mathrm{~mL}$ air keruh dengan konsentrasi pengeruh $1800 \mathrm{mg} \mathrm{L}^{-1}$.

Koagulan yang digunakan dalam penelitian ini yaitu fero sulfat yang kemudian diberi perlakuan variasi $\mathrm{pH}$ dan dosis koagulan. Pemilihan koagulan fero sulfat dikarenakan koagulan fero sulfat atau disebut juga copperas atau iron sulphate atau gula besi, merupakan garam termurah yang dapat digunakan untuk koagulasi. Tujuan dari penelitian ini yaitu menurunkan kadar torium dan radioaktivitas dalam limbah cair pengolahan monasit menggunakan koagulan fero sulfat.

\section{TATA KERJA}

\section{Bahan yang digunakan}

Bahan yang digunakan antara lain: limbah cair pengolahan monasit yang diperoleh dari kolam penampungan pilot plant PLUTHO; koagulan fero sulfat; asam klorida; natrium hidroksida; asam nitrat; asam sulfat; methanol; asam perklorat; torin; asam askorbat; akuades.

\section{Peralatan}

Peralatan yang digunakan dalam penelitian ini antara lain: mixer IKA Labortech; labu ukur dan peralatan gelas lainnya; neraca analitik merk Sartorius seri BSA224S-CW; pipet volumetrik; spatula; cawan porselen; hot plate; oven furnace merk Ney seri Vulcan D-550; planset; pH meter merk Metrohm seri 691; desikator; bulb; Spektrofotometer UV-Vis merk Shimadzu seri UV-2600; alat ukur radiasi Ludlum Model 1000 Scaler.

\section{Tahap Penelitian}

1) Karakterisasi limbah cair

a. Pengukuran $\mathrm{pH}$

pH meter merk Metrohm seri 691 yang digunakan dikalibrasi terlebih dahulu menggunakan buffer $\mathrm{pH} 4$ dan $\mathrm{pH} 10$. 
Kemudian elektroda $\mathrm{pH}$ meter dimasukkan ke dalam limbah cair untuk mengukur $\mathrm{pH}$.

b. Pengukuran torium

$>$ Pembuatan larutan standar torium

Pembuatan larutan standar Th dilakukan dengan mengencerkan $1 \mathrm{~mL}$ larutan standar Spex Torium 10.000 ppm ke dalam labu ukur $100 \mathrm{~mL}$ dan ditepatkan hingga tanda batas dengan aquades, diperoleh konsentrasi standar induk Th 100 ppm.

\section{Larutan $\mathrm{HNO}_{3}: \mathrm{HCLO}_{4}(1: 6)$}

Dicampurkan 1 volume $\mathrm{HNO}_{3}$ pekat dengan 6 volume $\mathrm{HCLO}_{4}$ pekat, kemudian diaduk sampai homogen.

$>$ Larutan $\mathrm{HCl}$ 1:1

Diencerkan 1 volume $\mathrm{HCl}$ pekat dengan 1 volume aquades, kemudian diaduk sampai homogen.

\section{$>$ Larutan Torin $0,1 \%$}

Ditimbang 1 gr torin kemudian dilarutkan dalam $1000 \mathrm{~mL} \mathrm{HCl} \mathrm{pH} \mathrm{0,8.}$

\section{Larutan Askorbat 5\%}

Ditimbang 5 gr asam askorbat dalam 100 mL aquades.

\section{Larutan HCL pH 0,8}

Ditambahkan sejumlah $\mathrm{HCl}$ ke dalam aquades sampai menunjukkan $\mathrm{pH} 0,8$.

Preparasi sampel

Sebanyak $25 \mathrm{~mL}$ limbah cair dipipet ke dalam piala gelas. Kemudian diuapkan hingga kering dan dilarutkan dengan $\mathrm{HCl} \mathrm{pH} 0,8$. Cairan dipindahkan ke dalam labu ukur 25 mL, ditambahkan $5 \mathrm{~mL}$ asam askorbat $5 \%$ dan $5 \mathrm{~mL}$ torin $0,1 \%$. Ditepatkan dengan $\mathrm{HCl}$ pH 0,8 hingga tanda tera.

\section{Larutan Blanko}

Larutan blanko dibuat dengan $5 \mathrm{~mL}$ asam askorbat $5 \%$ dan $5 \mathrm{~mL}$ torin $0,1 \%$ dipipet ke dalam labu ukur $25 \mathrm{~mL}$, kemudian ditepatkan dengan $\mathrm{HCl}$ pH 0,8 hingga tepat tanda tera.
Larutan standar torium

Dibuat deret standar torium dalam labu ukur dengan konsentrasi $0 ; 0,1 ; 0,5 ; 1 ; 5 ; 10$; $20 \mathrm{ppm}$. Kemudian ditambahkan $5 \mathrm{~mL}$ asam askorbat $5 \%$ dan $5 \mathrm{~mL}$ torin $0,1 \%$. Ditepatkan hingga tanda tera dengan $\mathrm{HCl} \mathrm{pH} 0,8$.

$>$ Pengukuran Th dengan Spektrofotometer UV-Vis

Setelah dibuat larutan sampel, standar maupun blanko didiamkan selama 30 menit. Serapan dari kompleks torium torin diukur dengan spektrofotometer pada panjang gelombang $545 \mathrm{~nm}$ slit 1 .

c. Pengukuran radioaktivitas

$>$ Preparasi limbah cair

Limbah cair yang dihasilkan dari pilot plant PLUTHO-PTBGN ditampung dalam drum dan kemudian disimpan selama 2 minggu.

\section{Preparasi sampel}

Sebanyak 2 L limbah cair ditambahkan 2 $\mathrm{mL} \mathrm{HNO}_{3}$, kemudian diuapkan di atas hotplate (jangan sampai mendidih) hingga volume $\pm 50 \mathrm{~mL}$. Setelah itu, dimasukkan ke dalam cawan porselen dan ditambahkan $1 \mathrm{~mL}$ $\mathrm{H}_{2} \mathrm{SO}_{4}$. Selanjutnya dilakukan penguapan kembali hingga kering. Dipanaskan dalam tungku/ tanur pada suhu $350^{\circ} \mathrm{C}$ selama 1 jam. Terakhir diletakkan dalam desikator.

$>$ Pengukuran radioaktivitas dengan Ludlum Model 1000 Scaler

Sampel digerus hingga halus kemudian ditimbang 0,5 gr di atas planset. Kemudian diteteskan dengan methanol dan dibiarkan menguap di bawah sinar UV. Pencacahan dilakukan dengan Ludlum Model 1000 Scaler. Radioaktivitas dihitung dengan menggunakan rumus:

$$
\begin{gathered}
\mathrm{C}_{\mathrm{A}}=\underline{\left(\mathbf{r}_{\mathrm{g}}-\mathbf{r}_{\mathrm{o}}\right)} \\
\mathrm{V} . \varepsilon
\end{gathered}
$$




$$
\varepsilon=\underline{\text { rs }- \text { ro }} \cdot 1000
$$

A

dimana:

$\mathrm{C}_{\mathrm{A}}=$ Konsentrasi RA

$r_{\mathrm{g}}=$ Laju cacah total cuplikan, cacah per detik

$\mathbf{r}_{\mathrm{o}}=$ Laju cacah latar, cacah per detik

$\mathrm{V}=$ Volume cuplikan uji yang setara dengan massa padatan dalam planset

$\varepsilon=$ Efisiensi pencacahan sumber kalibrasi tertentu

rs = Laju cacah sumber kalibrasi, cacah per detik

$\mathrm{A}=$ Aktivitas dari sumber radioaktif, dalam Becquerel

\section{2) Penentuan dosis optimal koagulan}

Pada penentuan dosis optimal koagulan dilakukan proses penentuan awal dosis koagulan yang didasarkan pada dosis terbaik pada penelitian sebelumnya [9]. Variasi dosis pada koagulan fero sulfat dalam peneltian yaitu: $25 ; 75 ; 125 ; 175 ; 225 ; 250 \mathrm{mg} / \mathrm{L}$. Sebelum proses koagulasi, limbah cair ditampung dalam sebuah drum yang kemudian diaduk terlebih dahulu agar homogen sebelum digunakan dalam penelitian. Setelah itu limbah cair dituang sebanyak $1000 \mathrm{~mL}$ ke dalam piala gelas. Proses koagulasi dilakukan dengan menggunakan mixer serta batang pengaduk dan dosis koagulan ditambahkan ke dalam piala gelas sesuai dengan dosis terbaik yang telah ditentukan. Proses koagulasi yang akan dilakukan mengacu pada penelitian oleh peneliti sebelumnya [12]. Proses koagulasi dilakukan dengan kecepatan $100 \mathrm{rpm}$ dan diaduk selama 3 menit kemudian dilakukan pengadukan lambat dengan kecepatan $20 \mathrm{rpm}$ dan diaduk selama 12 menit. Setelah itu didiamkan selama 15 menit agar terjadi pengendapan sempurna. Kemudian setelah mengendap, air berwarna bening (supernatan) dianalisis untuk menentukan kadar torium dan radioaktivitasnya.

3) Penentuan $\mathrm{pH}$ optimal proses koagulasi

Dosis koagulan optimal yang diperoleh kemudian diberi perlakuan $\mathrm{pH}$ yang bervariasi. Variasi $\mathrm{pH}$ yang digunakan yaitu: 7,$0 ; 7,5 ; 8,0$. Penentuan rentang $\mathrm{pH}$ ini didasarkan oleh keefektifan koagulan, $\mathrm{pH}$ efektif untuk koagulan fero sulfat yaitu 7,0 9,0 [8]. Dengan demikian rentang $\mathrm{pH} 7,0-$ 8,0 termasuk dalam rentang $\mathrm{pH}$ koagulan. Proses koagulasi dilakukan dengan langkah yang sama dengan tahap penentuan dosis optimal koagulan.

4) Analisis data

Analisis data pada tahap penentuan dosis optimal koagulan dan tahap penentuan $\mathrm{pH}$ optimal proses koagulasi diolah dengan menggunakan Microsoft Excel 2007. Dimana data tersebut dianalisis dengan menggunakan pendekatan grafik untuk menentukan proses koagulasi yang optimal. Sedangkan efisiensi penurunan kadar torium dan radioaktivitas dihitung menggunakan rumus:

$$
\% \text { Eff. Penurunan }=\frac{\mathrm{Cawal}_{\mathrm{C}}-\mathrm{C}_{\mathrm{akhir}}}{\mathrm{C}_{\mathrm{awal}}} \times 100 \%
$$

Ket:

$\mathrm{C}_{\mathrm{awal}}=$ Konsentrasi torium atau radioaktivitas mula-mula

$\mathrm{C}_{\mathrm{akhir}}=$ Konsentrasi torium atau radioaktivitas setelah koagulasi

\section{HASIL DAN PEMBAHASAN Karakteristik Limbah Cair}

Hasil pengamatan secara visual terhadap limbah cair pada penelitian ini yaitu berwarna kuning keruh serta memiliki bau yang menyengat seperti amoniak. Bau menyengat yang dikeluarkan dari limbah cair tersebut 
yaitu berasal dari larutan basa $\mathrm{NH}_{4} \mathrm{OH}$ yang digunakan pada proses pengendapan $\mathrm{U}, \mathrm{Th}$, dan logam tanah jarang. Senyawa $\mathrm{NH}_{4} \mathrm{OH}$ merupakan senyawa hipotesis (tidak stabil dan segera terurai) maka senyawa $\mathrm{NH}_{4} \mathrm{OH}$ akan terionisasi menjadi amonium dan air. Paramater lainnya seperti $\mathrm{pH}$, torium, dan radioaktivitas pada kondisi awal limbah cair dapat dilihat pada Tabel 1.

Tabel 1. Karakteristik limbah cair radioaktif awal

\begin{tabular}{lcc}
\hline \multicolumn{1}{c}{ Parameter } & Satuan & Jumlah \\
\hline $\mathrm{pH}$ & - & 11,69 \\
Torium & $\mathrm{mg} / \mathrm{L}$ & 0,73 \\
Radioaktivitas & $\mathrm{Bq} / \mathrm{g}$ & 1,35 \\
\hline
\end{tabular}

Pada Tabel 1 di atas, bila dilihat dari $\mathrm{pH}$ limbah cair kondisi awal, limbah cair tidak dapat dilepaskan langsung ke lingkungan karena nilai $\mathrm{pH}$ masih jauh di atas baku mutu. Berdasarkan Peraturan Menteri Lingkungan Hidup RI No. 5 Tahun 2014 tentang Baku Mutu Air Limbah, baku mutu pH limbah cair yang diizinkan agar dapat dilepaskan ke lingkungan yaitu 6,0 - 9,0 [13].

Kadar torium yang terdapat pada limbah cair dari hasil analisis diperoleh sebesar 0,73 $\mathrm{mg} / \mathrm{L}$. Asupan torium pada manusia setiap hari berkisar 0,41 - $1 \mu \mathrm{g}$ [14]. Setiap $1 \mu \mathrm{g} \mathrm{h}^{-1}$ asupan torium 98,1 persen, 1,6 persen dan 0,2 persen masing-masing terjadi melalui asupan makanan, air, dan udara [15]. Saat torium terserap ke dalam tubuh manusia, torium akan disimpan di banyak organ dan jaringan termasuk ginjal dan tulang [16]. Kadar torium di dalam limbah cair belum memiliki baku mutu di negara Indonesia. Penelitian yang telah dilakukan pada muara air laut yang berasal dari sungai Langat Malaysia, Kadar ${ }^{232} \mathrm{Th}$ di dalamnya yaitu $0,17 \mathrm{mg} / \mathrm{L}$ hingga $0,28 \mathrm{mg} / \mathrm{L}$ [17]. Sehingga diharapkan setelah proses koagulasi, kadar torium yang berada dalam limbah cair terjadi penurunan mencapai nilai ${ }^{232}$ Th seperti pada muara air laut yang berasal dari sungai Langat Malaysia.

Nilai radioaktivitas hasil analisis yaitu sebesar 1,35 Bq/g. Pada efek stokastik, dosis radiasi serendah apapun selalu terdapat kemungkinan untuk menimbulkan perubahan pada sistem biologi, baik tingkat molekul maupun sel. Semakin besar dosis paparan, semakin besar peluang terjadinya efek stokastik. Paparan radiasi dosis rendah dapat meningkatkan risiko kanker dan pewarisan yang secara statistik dapat dideteksi pada suatu populasi, namun tidak secara serta merta terkait dengan paparan invidu. Bila dikonversi menjadi dosis radiasi, nilai 1,35 $\mathrm{Bq} / \mathrm{g}$ sama dengan $16,27 \times 10^{-4} \mathrm{mGy}$. Pada organ mata manusia, apabila dosis radiasi terus menerus terakumulasi hingga $500 \mathrm{mGy}$, maka akan terjadi kekeruhan dan hilangnya sifat transparansi lensa mata. Selain itu juga, apabila sumsum tulang manusia terpapar dosis radiasi hingga $500 \mathrm{mGy}$ secara akumulatif, maka akan terjadi penekanan proses pembentukan komponen sel darah sehingga jumlahnya semakin menurun [18].

Nilai radioaktivitas awal dari limbah cair pada penelitian ini berada di atas Tingkat Klierens yang terdapat di dalam Perka Bapeten No.16 Tahun 2012 tentang Tingkat Klierens dimana definisi dari tingkat klierens adalah nilai yang ditetapkan oleh BAPETEN dan dinyatakan dalam konsentrasi aktivitas, pada atau di bawah nilai tersebut Zat Radioaktif Terbuka, Limbah Radioaktif, atau Material Terkontaminasi atau Teraktivasi dapat dibebaskan dari pengawasan [6]. Dalam Pasal 8 dijelaskan bahwa tingkat klierens untuk radionuklida buatan dan alam yang tidak dapat diidentifikasi ditetapkan sebesar $0,1 \mathrm{~Bq} / \mathrm{g}$. Dengan demikian penelitian dilanjutkan dengan tahap penentuan $\mathrm{pH}$ 
optimal proses koagulasi dengan dosis koagulan yang digunakan yaitu dosis optimal pada tahap ini.

\section{Dosis Optimal Koagulan Berdasarkan Penurunan Torium}

Dosis optimal ditentukan berdasarkan penurunan kadar torium dan radioaktivitas Hasil penelitian untuk mendapatkan dosis optimal pada koagulan fero sulfat berdasarkan penurunan kadar torium yang telah dilakukan dapat dilihat pada Gambar 1.

Pada Gambar 1 terlihat adanya penurunan kadar torium setelah proses koagulasi menggunakan fero sulfat. Penurunan kadar torium yang optimal yaitu pada dosis koagulan $125 \mathrm{mg} / \mathrm{L}$ menjadi 0,51 $\mathrm{mg} / \mathrm{L}$ dimana kondisi kadar torium awal limbah cair sebesar $0,72 \mathrm{mg} / \mathrm{L}$. Efisiensi penurunan kadar torium pada dosis tersebut yaitu 30,14\%. Pada Gambar 1 terlihat grafik yang fluktuatif, hal ini membuktikan bahwa koagulan dapat efektif dalam proses koagulasi apabila pada rentang $\mathrm{pH}$ efektif koagulan tersebut. Kondisi $\mathrm{pH}$ limbah cair awal cukup tinggi yaitu 11,69 dimana $\mathrm{pH}$ tersebut mendekati $\mathrm{pH}$ 12,0 (bersifat basa kuat). Kehadiran presipitat $\mathrm{Fe}(\mathrm{OH})_{3}$ mulai terlihat dari $\mathrm{pH}$ 4,0 dan pembentukan presipitat $\mathrm{Fe}(\mathrm{OH})_{3}$ ini akan meningkat pesat sejalan dengan peningkatan $\mathrm{pH}$ [19]. Pada $\mathrm{pH}$ $>12,0$, keberadaan presipitat $\mathrm{Fe}(\mathrm{OH})_{3}$ mulai berkurang serta mulai terbentuk spesies $\mathrm{Fe}(\mathrm{OH})_{4}{ }^{-}$terlarut. Oleh karena itu jumlah presipitat metal yang terbentuk akan bersaing dengan kehadiran spesies terlarut dan dalam jumlah yang tidak sebanyak pada $\mathrm{pH}$ optimum (kelarutan terendah).

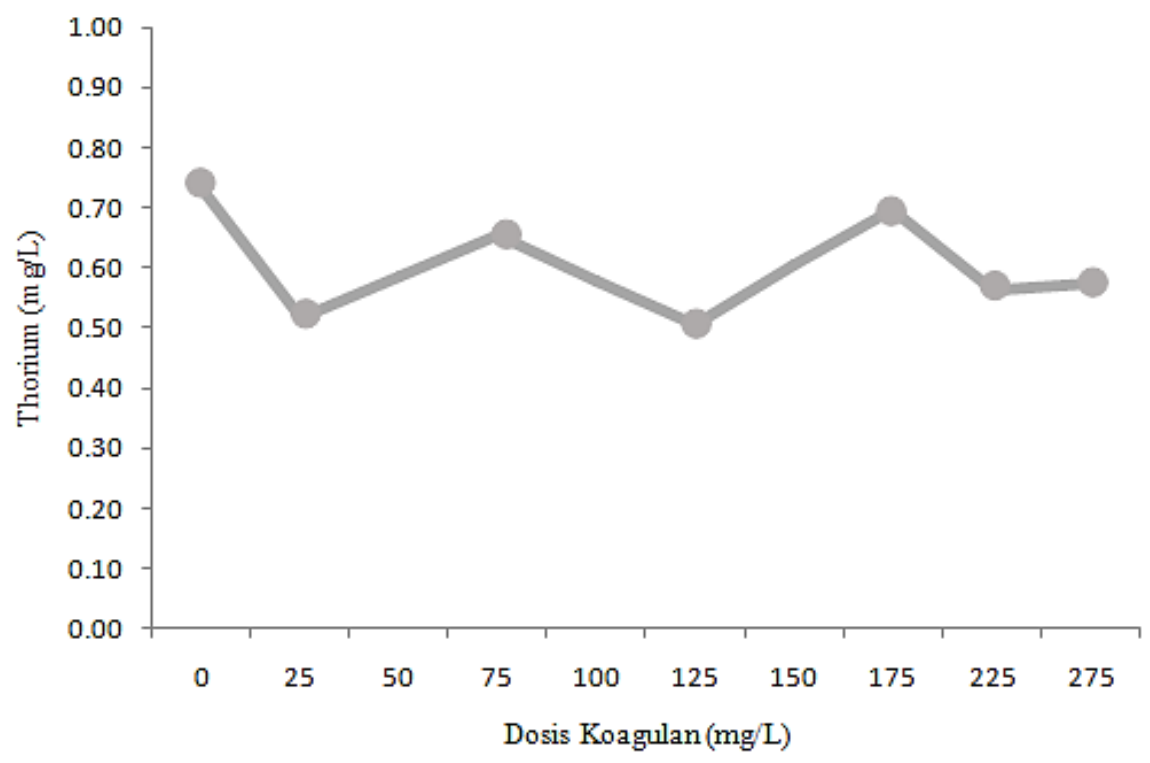

Gambar 1. Hasil analisis torium dalam penentuan dosis optimal koagulan.

Kisaran $\mathrm{pH}$ yang efektif untuk koagulan fero sulfat dalam proses koagulasi yaitu $\mathrm{pH}$ $7,0-9,0$ [8]. Koagulan fero sulfat pada $\mathrm{pH}$ 8,0 mampu menghasilkan efisiensi penurunan kadar logam kromium sebesar 100\% [20]. Proses koagulasi pada rentang $\mathrm{pH}$ efektif koagulan adalah mekanisme netralisasi muatan, dimana presipitat bermuatan positif akan teradsorpsi ke permukaan partikel koloid yang bermuatan negatif, dan hal ini akan menyebabkan perubahan karakteristik permukaan partikel, yang kemudian dilanjutkan dengan terjadinya mereduksi gaya tolak yang mampu memicu terjadinya proses 
koagulasi. Flok yang terbentuk dari mekanisme ini berukuran lebih kecil dan lebih halus dibandingkan dengan sweep coagulation [19].

Dosis optimal yang digunakan dalam perhitungan efisiensi penurunan kadar torium bukan merupakan dosis yang digunakan untuk tahap selanjutnnya karena yang telah diterangkan sebelumnya bahwa belum terdapat baku mutu kadar torium di dalam air.

\section{Dosis Optimal Koagulan Berdasarkan Penurunan Radioaktivitas}

Hasil penelitian untuk mendapatkan dosis optimal pada koagulan fero sulfat berdasarkan penurunan radioaktivitas yang telah dilakukan dapat dilihat pada Gambar 2.

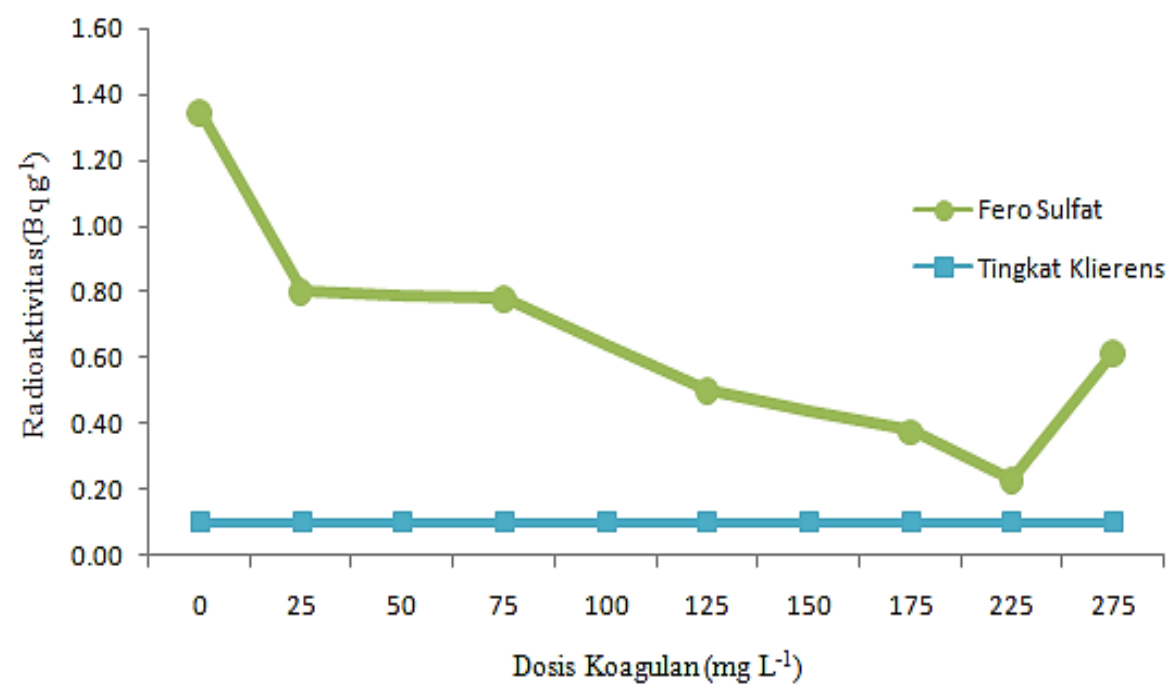

Gambar 2. Hasil analisis radioaktivitas dalam penentuan dosis optimal koagulan.

Pada Gambar 2 dapat dilihat grafik penurunan radioaktivitas pada koagulan fero sulfat. Perubahan radioaktivitas juga terjadi pada hasil analisis radioaktivitas setelah proses koagulasi dengan menggunakan koagulan fero sulfat. Penurunan radioaktivitas yang cukup signifikan terlihat yaitu pada dosis koagulan $225 \mathrm{mg} / \mathrm{L}$ dengan nilai radioaktivitas yang diperoleh sebesar 0,23 $\mathrm{Bq} / \mathrm{g}$. Oleh karena itu, efisiensi penurunan radioaktivitas menggunakan koagulan fero sulfat dengan dosis optimal adalah $82,96 \%$. Torium memiliki rantai peluruhan menghasilkan anak luruh yang memancarkan radiasi $\alpha, \beta$, dan $\gamma$ [21]. Adanya unsur radioaktif seperti torium, uranium, maupun anak luruh dari kedua unsur radioaktif tersebut pada limbah cair yang kemudian terperangkap pada struktur flok dari besi hidroksida $\mathrm{Fe}(\mathrm{OH})_{3}$ yang telah terbentuk setelah penambahan koagulan fero sulfat. Terjebaknya atau terperangkapnya unsurunsur radioaktif tersebut oleh presipitat logam hidroksida maka semakin besar efisiensi sweep coagulation yang terjadi sehingga nilai radioaktivitas semakin menurun. Pada variasi dosis di bawah dosis optimalnya nilai radioaktivitas lebih tinggi karena dengan dosis yang lebih sedikit maka jumlah flok besi hidroksida yang terbentuk juga sedikit sehingga mekanisme sweep coagulation pada partikel koloid atau suspensi tidak optimal. Sedangkan pada variasi dosis koagulan di atas dosis optimal nilai radioaktivitas kembali meningkat. Hal ini disebabkan dengan penambahan koagulan yang berlebih akan 
meningkatkan kation di dalam limbah cair sehingga akan terjadi restabilisasi partikel koloid atau suspensi karena muatan partikel menjadi positif dan terjadi gaya tolak menolak kembali [12].

\section{pH Optimal Proses Koagulasi Berdasarkan Penurunan Torium}

Derajat keasaman atau $\mathrm{pH}$ optimal dapat ditentukan berdasarkan penurunan parameter kadar torium dan radioaktivitas. Hasil penelitian penurunan kadar torium yang telah dilakukan dapat dilihat pada Gambar 3.

Dosis optimal koagulan fero sulfat yang digunakan untuk tahap ini sebesar $225 \mathrm{mg} / \mathrm{L}$. Pada grafik koagulan fero sulfat di atas, kondisi $\mathrm{pH}$ dimana penurunan kadar torium yang optimal yaitu pada $\mathrm{pH} 8,0$. Pada $\mathrm{pH} 8,0$ terlihat adanya penurunan $\mathrm{pH}$ optimal dengan nilai kadar torium setelah koagulasi sebesar 0,40 $\mathrm{mg} / \mathrm{L}$ dari kadar torium awal sebesar $0,73 \mathrm{mg} / \mathrm{L}$, sehingga efisiensi penurunan kadar torium yaitu 45,20\%. Hal tersebut dikarenakan koagulan fero sulfat akan bereaksi dengan natural alkalinity yang terdapat dalam air membentuk ion aquometalik $\mathrm{Fe}(\mathrm{OH})_{2}$ atau flok yang masih bersifat larut sebagian. Jika kondisi air mempunyai $\mathrm{pH}$ lebih besar 6, maka ion $\mathrm{Fe}(\mathrm{OH})_{2}$ akan segera teroksidasi menjadi $\mathrm{Fe}(\mathrm{OH})_{3}$ dan dengan oksigen yang terlarut dalam air membentuk flok yang sangat tidak larut dengan reaksi seperti berikut [22]:

$$
4 \mathrm{Fe}(\mathrm{OH})_{2}+\mathrm{O}_{2}+2 \mathrm{H}_{2} \mathrm{O} \rightarrow 4 \mathrm{Fe}(\mathrm{OH})_{3}
$$

(larut sebagian) (larut)

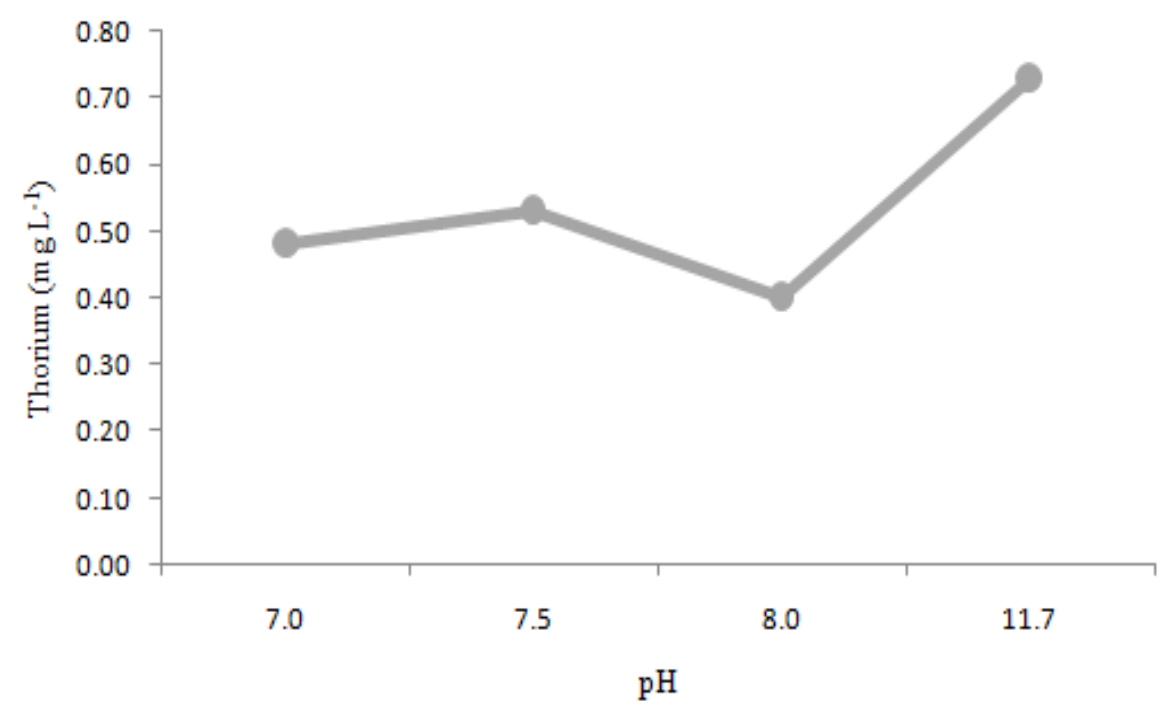

Gambar 3. Hasil analisis kadar torium dalam penentuan $\mathrm{pH}$ optimal proses koagulasi.

Konstanta kelarutan minimal untuk hidroksida logam adalah pada kisaran $\mathrm{pH} 8$ [19]. Pada kelarutan minimum, logam hidroksida kemudian menjadi jenuh dan mengendap. Endapan logam hidroksida berupa $\mathrm{Fe}(\mathrm{OH})_{3}$ akan semakin banyak terbentuk pada titik kelarutan minimum tersebut. Sehingga semakin banyak terbentuk
$\mathrm{Fe}(\mathrm{OH})_{3}$, maka semakin besar efisiensi sweep coagulation yang terjadi. Selain itu, titik isoelektrik yaitu titik dimana nilai potensial zeta dari logam hidroksida $\mathrm{Fe}(\mathrm{OH})_{3}$ mendekati 0 adalah $\mathrm{pH}$ 8,3 dimana proses koagulasi akan berjalan optimal pada nilai potensial zeta mendekati nilai isoelektrik [23]. Dengan demikian, dengan adanya 
presipitat hidroksida logam maka mekanisme pemerangkapan partikel koloid atau suspensi dalam endapan akan cepat terjadi. Partikelpartikel koloid atau suspensi yang ada akan terperangkap pada struktur flok hidroksida logam dan terbawa. Dengan kata lain, unsurunsur torium dan uranium yang bersifat radioaktif dalam bentuk partikel koloid atau suspensi akan terperangkap pada struktur flok $\mathrm{Fe}(\mathrm{OH})_{3}$ dan mengendap sehingga akan menurunkan torium limbah cair. Kadar torium pada $\mathrm{pH} 7,0$ dan 7,5 lebih tinggi dibandingkan kadar torium pada $\mathrm{pH} 8,0$. Hal ini dikarenakan presipitat $\mathrm{Fe}(\mathrm{OH})_{3}$ yang terbentuk belum optimal ataupun $\mathrm{Fe}(\mathrm{OH})_{3}$ yang terbentuk memiliki tingkat kelarutan sedang di dalam air limbah sehingga partikel koloid dan suspensi yang berada dalam limbah terperangkap dalam presipitat dalam jumlah sedikit.

\section{pH Optimal Proses Koagulasi Berdasarkan Penurunan Radioaktivitas}

$\mathrm{pH}$ optimal juga ditentukan berdasarkan penurunan parameter radioaktivitas. Hasil penelitian untuk penurunan radioaktivitas yang telah dilakukan dapat dilihat pada Gambar 4.

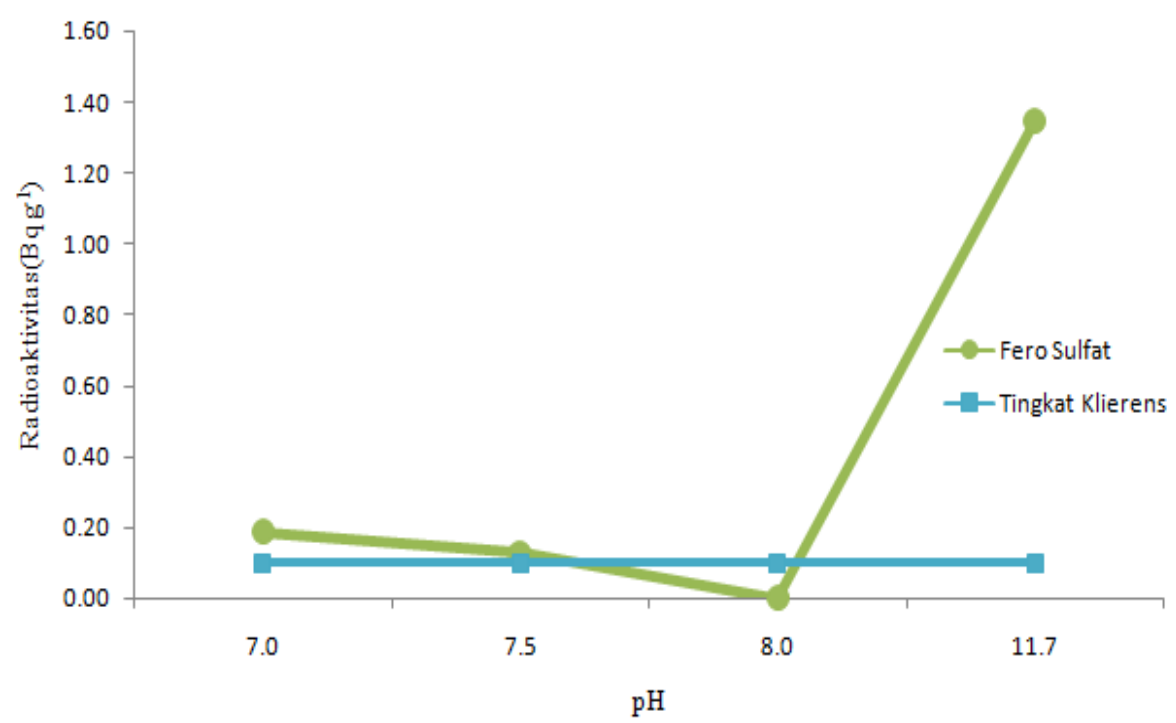

Gambar 4. Hasil analisis radioaktif dalam penentuan $\mathrm{pH}$ optimal proses koagulasi.

Bila dilihat dari Gambar 4 di atas, grafik koagulan fero sulfat juga terjadi penurunan radioaktivitas paling optimal pada $\mathrm{pH} 8,0$. Pada pH 8,0 nilai radioaktivitas yang diperoleh setelah proses koagulasi adalah 0 $\mathrm{Bq} / \mathrm{g}$ dari radioaktivitas awal yaitu sebesar $1,35 \mathrm{~Bq} / \mathrm{g}$. Pengukuran radioaktivitas awal limbah cair dilakukan sebanyak dua kali pengukuran sehingga nilai $1,35 \mathrm{~Bq} / \mathrm{g}$ adalah nilai rata-rata (mean) dari nilai dua kali pengukuran tersebut. Dengan nilai radioaktivitas tersebut, dapat dikatakan bahwa efisiensi penurunan radioaktivitas yang didapatkan adalah sebesar $100 \%$. Nilai radioaktivitas hasil analisis tersebut telah mencapai nilai di bawah tingkat klierens yang mengacu pada Perka Bapeten No.16 Tahun 2012 tentang Tingkat Klierens yaitu sebesar $0,1 \mathrm{~Bq} / \mathrm{g}$ sehingga limbah cair setelah proses koagulasi menggunakan koagulan fero sulfat dapat dilepaskan langsung ke badan air penerima seperti sungai, danau, waduk, dan lain-lain. 
Pada tahap penentuan $\mathrm{pH}$ optimal ini diperoleh efisiensi penurunan radioaktivitas yang jauh lebih besar bila dibandingkan pada tahap sebelumnya. Pada $\mathrm{pH} 8,0$, proses koagulasi yang terjadi yaitu melalui mekanisme sweep coagulation atau penjebakan dalam presipitat. Unsur-unsur torium, uranium, dan anak luruhnya baik dalam bentuk partikel koloid atau suspensi akan terperangkap pada struktur flok $\mathrm{Al}(\mathrm{OH})_{3}$ atau $\mathrm{Fe}(\mathrm{OH})_{3}$ dan mengendap sehingga akan menurunkan radioaktivitas pada limbah cair.

\section{KESIMPULAN}

Proses koagulasi yang dilakukan pada limbah cair pengolahan monasit yang dihasilkan di pilot plant PLUTHO, Pusat Teknologi Bahan Galian Nuklir-BATAN dengan menggunakan koagulan fero sulfat dengan variasi dosis dan $\mathrm{pH}$ menunjukkan adanya penurunan kadar torium dan radioaktivitas. Pada kondisi optimal diperoleh penambahan koagulan fero sulfat dengan dosis $225 \mathrm{mg} / \mathrm{L}$ dan $\mathrm{pH} \quad 8,0$ dapat menurunkan kadar torium 45,20\% dan radioaktivitas $100 \%$.

\section{UCAPAN TERIMA KASIH}

Ucapan terima kasih kami sampaikan kepada Pusat Teknologi Bahan Galian Nuklir-Batan yang telah menyediakan tempat penelitian serta bahan dan peralatan yang dibutuhkan dalam penelitian.

\section{DAFTAR PUSTAKA}

[1] S. J. Suprapto, "Tinjauan Tentang Unsur Tanah Jarang", Buletin Sumber Daya Geologi, Pusat Sumberdaya Geologi, Bandung, 1-11,2009.

[2] Sumarni, R. Prassanti, K. Trinopiawan, Sumiarti, H. L. Nuri, "Penentuan Kondisi Pelarutan Residu dari Hasil Pelarutan Parsial Monasit Bangka", Eksplorium, 32(1), 115-124, 2011.

[3] M. Anggraini, "Proses Pemisahan Unsur Radioaktif dan Unsur Logam Tanah Jarang Pada
Slag II Peleburan Timah", Tesis Institut Teknologi Sepuluh November, Surabaya, 2016.

[4] I. Gaballah, E. Allain, M. Meyer-Joly, K. Malau, "A possible Methode for the Characterization of Amophous Slags : Recovery of Refractory Metal Oxide from Tin Slags", Metall. Trans. B, 249259, 1992.

[5] Pusdiklat Batan, "Prinsip Dasar Pengukuran Radiasi” Modul Pusdiklat Badan Tenaga Nuklir Nasional, Jakarta, 2015.

[6] [Perka Bapeten] Peraturan Kepala Badan Pengawas Tenaga Nuklir No 16 Tahun 2012. 2012. Tingkat Klierens.

[7] C. Suhendar, "Penggunaan Tanah dalam Penurunan Konsentrasi Ion $\mathrm{Ni}^{2+}$ dan $\mathrm{Cr}^{6+}$ dari Limbah Elektroplating dengan Metode Jar Test", Tesis Institut Pertanian Bogor, Bogor, 2012.

[8] D. P. Marisi, "Optimalisasi Jenis Koagulan dalam Pengolahan Limbah Cair Bahan Pewarna Tekstil Melalui Proses Koagulasi dan Flokulasi”, Skripsi Universitas Sahid, Jakarta, 2012.

[9] S. Yuliati, "Proses Koagulasi-Flokulasi pada Pengolahan Tersier Limbah Cair PT. Capsugel Indonesia" Skripsi Institut Pertanian Bogor, Bogor, 2006.

[10] Z. Salimin, "Proses Kimia Pengolahan Limbah Korosif Radioaktif dari Fabrikasi Bahan Bakar Nuklir", Prosiding Pertemuan dan Presentasi Ilmiah, Yogyakarta, 1995.

[11] S. Putra, S. Rantjono, T. Arifiansyah, " Optimasi Tawas dan Kapur untuk Koagulasi Air Keruh dengan PenandaI-131", Prosiding Seminar Nasional V SDM Teknologi Nuklir, Yogyakarta, 2009.

[12] P. P. D. K. Wulan, Dianursanti, M. Gozan, W. A. Nugroho, "Optimasi Penggunaan Koagulan pada Pengolahan Air Limbah Batubara”, Prosiding Seminar Nasional Teknik Kimia Kejuangan, Yogyakarta, 2010.

[13] [Permen LH RI] Peraturan Menteri Lingkungan Hidup Republik Indonesia No 5 Tahun 2014. 2014. Baku Mutu Air Limbah.

[14] Z. Pietrzak-Flis, L. Rosiak, M. M Suplinska, E. Chrzanowski dan S. Dembinska, "Daily Intakes of U-238, U-234, Th-232, Th-230, Th-228 and Ra-226 in The Adult Population of Central Poland", Sci Tot Environ, 273(1), 163-169, 2001.

[15] I. M. Fisenne, P. M. Perry, K. M. Decker, H. W. Keiller, "The Daily Intakes of U-234,235,238 Th232, Th-228,230,232 and Ra-226,228 by New York City Residents", Health Phys, 53(1), 357363, 1987.

[16] L. Dominic, P. P. Ana, M. Leonora, L. Chunsheng, C. Jing, R. J. Cornett, "Age Dependence of Natural Uranium and Thorium Concentration in Bone", Health Physics., 92(2), 119-126, 2007.

[17] Z. Hamzah, T. N. T. M. Rosli, A. Saat and K. Wood, “An Assesment Of Natural Radionuclides 
In Water Of Langat River Estuary, Selangor", in Proceeding Advancing Nuclear Research and Energy Development., 1458(1), 228-234, 2014.

[18] M. Montana, A. Camacho, R. Devesa, I. Valles, R. Cespedes, I. Serrano, S. Blazquez, V. Barjola. "The Presence of Radionuclides in Wastewater Treatment Plants in Spain and Their Effect on Human Health", Journal of Cleaner Production., 60(1), 77-82, 2013.

[19] S. W. Rachmawati, B. Iswanto, Winarni, "Pengaruh pH pada Proses Koagulasi dengan Koagulan Aluminium Sulfat dan Ferri Klorida", Jurnal Teknologi Lingkungan, 5(2), 40-45, 2009.

[20] P. L. Hariani, N. Hidayati, M. Oktaria, "Penurunan Konsentrasi Cr(VI) Dengan Air
Dengan Koagulan $\mathrm{FeSO}_{4}$ ", Jurnal Penelitian Sains, 12(2C), 122801-1228045, 2009.

[21] I. A. Bhatti, M. A. Hayat, and M. Iqbal, "Assesment of Thorium In The Environment (A Review)", Jurnal Chemistry Social Pakistan, 34(4), 1012-1022, 2012.

[22] Sunardi dan K. Wijayanti, "Pengolahan Limbah Besi Bengkel Bubut Menjadi Koagulan untuk Penjernihan Air", Prosiding Seminar Nasional KPK II, Surakarta, 2010.

[23] W. Donald, Soundstrom, H.E. Klei, Wastewater Treatment. New Jersey: Prentice-Hall Int. Inc, 1979. 